\title{
PERILAKU IBU DALAM PENDIDIKAN SEKS PADA ANAK USIA 3-5 TAHUN
}

\author{
Mother Behavior In Sex Education In Children 3-5 Years Old \\ Sab'ngatun $^{1}$, Sri Suparti ${ }^{2}$, Tri Wahyu Agustina ${ }^{3}$ \\ STIKES Mamba'ul 'Ulum Surakarta \\ sabngatun@yahoo.com
}

\begin{abstract}
ABSTRAK
Latar Belakang : Pendidikan seksual bagi anak merupakan suatu kebutuhan. Pengetahuan tentang seks pada anak dapat mencegah terjadinya penyimpangan seksual. Pendidikan seks harus ditanamkan oleh orang tua sejak dini agar anak tahu tentang seks.

Tujuan : Penelitian ini bertujuan untuk mengetahui perilaku ibu dalam pendidikan seks pada anak usia 3-5 tahun.

Metode : Penelitian ini merupakan penelitian diskriptif dengan pendekatan crossectional, Sampel dalam penelitian in adalah semua populasi yaitu semua ibu yang memiliki anak usia 3-5 tahun di Posyandu RW 02 Desa Pranan, Polokarto, Sukoharjo sebanyak 47 responden. Alat pengumpul data berupa kuisioner. Analisa data disajikan dengan distribusi frekuensi.

Hasil : Hasil penelitian ini mayoritas usia ibu 26-35 tahun sebanyak 29 responden $(61.7 \%)$, berpendidikan menengah sebanyak 23 responden $(49 \%)$ dan perilaku ibu dalam memberikan pendidikan seks pada anak usia 3-5 tahun pada kategori baik sebanyak 20 responden $(42,6 \%)$.
\end{abstract}

Kesimpulan : Perilaku ibu dalam memberikan pendidikan seks pada anak usia 35 tahun pada kategori baik.

Kata Kunci: Perilaku, pendidikan seks

\begin{abstract}
Background: Sexual education for children is a necessity. Knowledge about sex in children can prevent sexual deviations. Sex education must be instilled by parents early so that children know about sex.

The aim : This study aims to determine the behavior of mothers in sex education in children aged 3-5 years.

Method: This study is a descriptive study with a crossectional approach. The sample in this study is all populations, namely all mothers who have children aged 3-5 years in Posyandu RW 02, Pranan Village, Polokarto, Sukoharjo, 47 respondents. Data collection tool in the form of questionnaires. Data analysis is presented by frequency distribution.

Results: The results of this study were the majority of mothers aged 26-35 years as many as 29 respondents (61.7\%), secondary education as many as 23
\end{abstract}


respondents (49\%) and maternal behavior in providing sex education to children aged 3-5 years in the good category as many as 20 respondents ( $42.6 \%)$.

Conclusion: The behavior of mothers in providing sex education in children aged 3-5 years in the good category.

Keywords: Behavior, sex education

\section{PENDAHULUAN}

Komisioner (Komisi Perlindungan Anak Indonesia) mengungkapkan bahwa data kekerasan seksual pada anak tahun 2015 sebanyak 218 kasus, pada tahun 2016 terdapat 120 kasus, tahun 2017 tercatat 393 korban dan 66 pelaku (KPAI, 2017). Pada awal tahun 2018 hingga akhir Februari jumlah kekerasan seksual pada anak di Indonesia mencapai 117 kasus (Akbar, 2018). Kekerasan seksual banyak terjadi di sekolah dan dilakukan pendidik terutama di sekolah dasar dan menengah pertama. pada tahun 2018 dari total 177 orang korban kekerasan seksual sebanyak 135 orang diantaranya merupakan anak laki-laki, pelaku membujuk anak-anak dengan iming-iming memberikan kesaktian, ilmu kebal dan memberikan tawaran pengobatan gaib (Amirullah, 2018). Korban rata-rata usia 13 tahun dan paling muda usia 2 tahun. Dari seluruh kasus kekerasan pada anak, 58\% kasus kekerasan seksual, pelakunya adalah orang tedekat anak, dimana 44\% dilakukan di lingkungan rumah, 22\% di lingkungan sekolah. 20\% di ruang public.

Pendidikan seksual bagi anak sejak usia dini merupakan kebutuhan. Informasi yang diberikan diantaranya pengetahuan tentang fungsi organ reproduksi dengan menanamkan moral, etika, komitmen, termasuk agama agar tidak terjadi penyalahgunaan organ reproduksi tersebut. Pengetahuan tentang seks pada anak dapat mencegah terjadinya penyimpangan seksual yang dilakukan oleh anak. Selain itu, pendidikan seks pada anak juga dapat mencegah anak menjadi korban pelecehan seksual. Dengan dibekali pengetahuan tentang seks, mereka menjadi mengerti perilaku mana yang tergolong pelecehan seksual dan mana yang bukan kategori itu, pengetahuan tentang seks dapat mencegah anak mencoba tindakan yang seharusnya belum boleh mereka lakukan karena ketidaktahuannya. Dengan anak tahu, mereka mampu menolak, menghindar, mengadu kepada orang terdekat jika ada seseorang yang melakukan tindakan kejahatan seksual. Mencegah Kejahatan seksual harus menjadi gerakan bersama, gerakan kultural, gerakan sosial dan gerakan penyadaran. (Republika, 2015)

Seringkali orangtua merasa tabu dan takut anaknya tahu akan seks. Padahal, pendidikan seks sejak dini sangat penting bagi anak. Komisioner Komisi Perlindungan Anak Indonesia (KPAI), Bidang Hak Sipil dan Partisipasi Anak, menerangkan anak harus diberitahu bagian tubuh yang perlu dijaga dan langkah yang dilakukan, jika ada orang yang melecehkan dirinya. Orang tua harus mulai mengenalkan anggota tubuh mana yang boleh disentuh orang lain, jangan menyamarkan kata penis dan vagina, orang tua pun harus menjelaskan secara gambling tentang pertumbuhan fisik dan bagian tubuh yang harus dilindungi. Pengawasan dan pemantauan menjadi tugas bersama baik keluarga dalam 
menjelaskan pendidikan seks sesuai pemehaman dan usianya. Begitu juga dengan dunia pendidikan ada pembahasan tentang organ tubuh anak yang perlu dilindungi. (KPAI, 2018)

Ibu merupakan madrasah pertama bagi anak, sehingga ibu diharapkan memberikan pendidikan seks pada anak sejak usia dini. Pendidikan seks yang diberikan pada anak usia dini mampu memberikan pengetahuan anak seputar seks dan akan membentengi anak dari peilaku kekerasan seksual maupun penyimpangan seksual. Beberapa pokok pendidikan seks dalam perspektif islam yang dapat dilakukan oleh ibu terhadap anaknya adalah mengejarkan toilet training, menanamkan rasa malu pada anak, menanamkan jiwa feminim pada anak perempuan dan maskulin pada anak lelaki, memisahkan tempat tidur, mengenalkan waktu berkunjung, mengenalkan mahram, mendidik anak selalu menjaga pandangan mata, mendidik anak agar tidak melakukan ihtilat, mendidik anak agar tidak melakukan khalwat, mendidik etika berhias, ihtilam dan haid (Muhsinin, 2017)

Menurut penelitian Yafie (2017) pendidikan seks perlu ditanamkan orang tua, dan harus didasari dengan nilai agama dan moral. Tapi ironisnya banyak orang tua yang acuh tak acuh dan tabu membahas masalah seks. Hal ini menunjukkan pentingnya memahami pendidkan seks pada anak usia dini. Pendidikan seks kurang menjadi perhatian orang tua sehingga mereka menyerahkan ke pendidikan termasuk pendidikan sks di sekolah. Seharusnya pendidikan seks pada anak usia dini merupakan tanggung jawab orang tua, sedangkan sekolah hanya sebagai pelengkap dalam memberikan informasi pada anak. Prinsip dalam memberikan pendidikan seks pada anak adalah siap member pendidikan seks tiap saat, member teladan dan bimbingan lisan secara bersama, menjawab pertanyaan dan member jawaban yang tepat, penenkanan untuk menghormati dan privacy.

Berdasarkan hasil studi pendahuluan 9 dari 10 ibu belum memberikan pendidikan seksual pada anak usia 3-5 tahun. Berdasarkan latar belakang di atas maka penulis mengambil judul "Perilaku Ibu Dalam Pendidikan Seks Pada Anak Usia 3-5 tahun.

\section{METODE PENELITIAN}

Penelitian ini merupakan penelitian diskriptif dengan pendekatan crossectional. Dalam penelitian ini semua populasi dijadikan sebagai sampel (subjek penelitian), subjek penelitiannya adalah semua ibu yang memiliki anak usia 3-5 tahun di Posyandu RW 2 Desa Pranan, Polokarto, Sukoharjo sebanyak 47 orang, Alat pengumpulan data berupa kuisioner dan penelitian ini disajikan dalam bentuk distribusi frekuensi. 


\section{HASIL DAN PEMBAHASAN}

Tabel 1. Distribusi Frekuensi Karakteristik responden

\begin{tabular}{llcc}
\hline No & \multicolumn{1}{c}{ Karakteristik } & Frekuensi & Prosentase (\%) \\
\hline \multicolumn{2}{l}{ Usia } & & \\
2 & 16-25 tahun & 6 & 12.8 \\
3 & 26-35 tahun & 29 & 61.7 \\
& 36-45 tahun & 12 & 25.5 \\
\multicolumn{2}{c}{ Jumlah } & 47 & 100 \\
& Pendidikan & & \\
1 & Dasar & 8 & 17 \\
2 & Menengah & 23 & 49 \\
3 & Tinggi & 16 & 34 \\
& $\quad$ Jumlah & 47 & 100 \\
\hline
\end{tabular}

Tabel 2. Distribusi Frekuensi Perilaku Ibu Dalam Pendidikan Seks Pada Anak Usia 3-5 Tahun

\begin{tabular}{llcc}
\hline No & $\begin{array}{c}\text { Pemberian Pendidikan Seks } \\
\text { Anak Usia 3-5 tahun }\end{array}$ & Frekuensi & Prosentase (\%) \\
\hline 1 & Kurang & 8 & 17,0 \\
2 & Cukup & 19 & 40,4 \\
3 & Baik $\quad$ Jumlah & 20 & 42,6 \\
& & 47 & 100 \\
\hline
\end{tabular}

Berdasarkan tabel 1. Mayoritas responden berumur 26-35 tahun sebanyak 29 responden $(61.7 \%)$ dan berpendidikan menengah sebanyak 23 responden (49\%). Menurut YB Mantra pendidikan dapat mempengaruhi seseorang termasuk juga perilaku seseorang, makin tinggi pendidikan seseorang makin mudah menerima informasi. Menurut Elisabet $\mathrm{BH}$ usia adalah umur seseorang terhitung mulai saat dilahirkan sampai berulang tahun, menurut Hurclok (1998) semakin cukup umur, tingkat kematangan dan kekuatan seseorang akan lebih matang dalam berfikir dan bekerja, seseorang yang lebih dewasa lebih dipercaya, hal ini sebagai pengalaman dan kematang jiwa. (Wawan, 2011).

Berdasarkan tabel 2. Perilaku ibu dalam pendidikan seks pada anak usia 35 tahun mayoritas pada kategori baik sebanyak 20 responden (42.6\%). Perilaku adalah proses interkasi individu dalam tindakan atau perilaku suatu organism yang dapat diamati dan dipelajari. Faktor yang mempengaruhi perilaku yaitu faktor predisposisi mencakup faktor genetic, pengetahuan, tingkat pendidikan, sosio psikologis, sosial ekonomi dan pemberian informasi; faktor pemungkin mencakup sarana dan prasarana dan faktor penguat meliputi faktor sikap dan perilaku tokoh masyarakat, tokoh agama juga petugas kesehatan. (Notoatmodjo, 2014)

Perilaku dan gejala perilaku yang tampak pada kegiatan organisme (makhluk hidup) dipengaruhi oleh faktor genetik (keturunan) dan lingkungan Faktor keturunan merupakan modal untuk perkembangan perilaku makhluk hidup untuk selanjutnya, sedangkan lingkungan merupakan lahan untuk perkembangan perilaku selanjutnya.(Wawan, 2011)

Pendidikan seksual perlu diberikan kepada anak usia dini karena pada usia ini anak akan lebih mampu untuk menyerap apa yang didengar, dilihat dan 
dirasakan. (Nawita, 2013). Sesuatu yang di dapatkan anak waktu kecil akan dibawanya atau akan direkam di memorinya sampai dewasa maka perlu untuk orang tua memberikan pendidikan seksual sejak anak usia dini atau usia 3-5 tahun guna mencegah terjadinya penyalahgunaan organ reproduksi dan mencegah terjadinya eksploitasi seksual baik masa anak atau masa dewasa. Hal ini diperlukan peran orang tua dalam memberikan pendidikan seks usia dini agar anak tidak menyimpang dalam kejahatan seks.

Hasil penelitian Aprilia (2015) praktek pemberian pemahaman pendidikan seks usia dini, ibu memberikan materi yang sudah diberikan kepada anaknya, karakteristik responden berusia 33-39 tahun dan berpendidikan diploma dan sarjana, pengetahuan ibu mengenai pendidikan seks cenderung masih kurang, sikap ibu terhadap pemberian pemahaman pendidikan seks pada anak sudah baik, tapi sebagian besar merasa bahwa pendidikan seks maih dianggap tabu untuk diberikan pada anak, pihak yang paling membantu mempengaruhi ibu dalam memberikan pendidikan seks pada anak usia dini adalah ayah atau suami ibu, pemberian pemehaman pendidikan seks untuk anak usia pra sekolah bagi ibu belum membutuhkan fasilitas yang menunjang, niat ibu berniat untuk memberikan pendidikan seks pada anak pra sekolah hampir semua ibu berusaha memperoleh materi terkait pemahaman pendidikan seks anak usia pra sekolah, perilaku seksual pada anak yang muncul adalah anak suka mandi berlama-lama di kamar mandi.

Hasil penelitian Hertia (2017) menunjukkan bahwa anak rentan terhadap tindakan kekerasan seksual sehingga ibu membatasi anak untuk bermain di luar, ibu merasa bahwa permasalahan kekerasan seksual merupakan hal yang serius sehingga sejak dini ibu harus sudah mengajarkan tentang sentuhan boleh dan yang tidak boleh dan hal apa yang harus dilakukan bila ada orangb yang menyentuh bagian yang tidak boleh disentuh. Ibu merasa hambatan yang dialami adalah bahasa yang digunakan untuk mnyebutkan alat kelamin, orang tua harus memberikan pengawasan serta menjadi contoh teladan yang baik bagi anak dalam hal seksualitas sehingga anak mampu memahami dan mengaplikasikan seksualitas dengan baik.

Hasil penelitian Sugiasih (2011) kekkuatan yang dimiliki subyek adalah usia ibu tergolong muda sehingga lebih mudah menerima informasi baru, pekerjaan sebagai ibu rumah tangga sehingga mempunyai banyak waktu dengan anak, mempunyai sikap yang positif terhadap pendidikan seksual pada anak usia 3-5 tahun, sebagian ibu sudah mngenalkan bagian-bagian tubuh termasuk alat kelaminnya, ibu sudah berusaha menjelaskan perbedaan alat kelamin antara lelaki dan perempuan; sedangkan hambatan yang dimiliki subyek dalam memberikan pendidikan seksual adalah merasa malu saat harus menanggapi pertanyaan anak tentang perbedaan alat kelaminnya dengan orang dewasa, jika harus menanggapi pertanyaan anak tentang perbedaan alat kelaminnya dengan alat kelamin orang dewasa ibu merasa takut kalau anaknya bertanya terus; kelemahan yang dimiliki subyek adalah tingkat pendidikan menengah ke bawah, pengetahuan tentang pendidikan seksual anak usia 3-5 tahun masih kurang; peluang yang dimiliki subyek adalah subyek menyadari akan pentingnya pendidikan seksual untuk anak usia 3-5 tahun. 


\section{SIMPULAN DAN SARAN}

\section{Simpulan}

Perilaku ibu dalam pendidikan seks pada anak usia 3-5 tahun mayoritas pada kategori baik sebanyak 20 responden $(42,6 \%)$ dengan mayoritas berpendidikan menengah dan berusia 26-35 tahun.

\section{Saran}

Orang tua sebaiknya segera memberikan pendidikan seksual pada anak sejak dini agar anak mengerti tentang organ tubuh yang harus dilindungi. Bagi peneliti selanjutnay diharapkan dapat meneliti faktor-faktor yang mempengaruhi perilaku ibu dalam pemberian pendidikan seks pada abak usia dini.

\section{DAFTAR PUSTAKA}

Akbar, NA. 2018. Sepanjang Tahun 2018, Ada 100 Lebih Korban Kekerasan Seksual Terhadap Anak di Indonesia, http://jakarta.tribunnews.com/2018/03/19/sepanjang-tahun-2018-ada-100lebih-korban-kekerasan-seksual-terhadap-anak-di-indonesia\#gref

Aprilia, A. 2015. Perilaku Ibu dalam Memberikan Pendidikan Seks Usia Pra Sekolah (Study Deskriptif Eksploratif di TK IT Bina Insani Kota Semarang. Jurnal Kesehatan Masyarakat. Vol 3 No 1 Januari 2015. Semarang : Universitas Diponegoro.

https://ejournal3.undip.ac.id/index.php/jkm/article/view/11555/11213

Amirullah, 2018. KPAI: Pelanggaran Hak Anak di 2018 Didominasi Tindak Kekerasan https://nasional.tempo.co/read/1159391/kpai-pelanggaran-hak-anak-di2018-didominasi-tindak-kekerasan

Hertia, Masfa'ah. 2017. Perilaku ibu dalam memberikan pendidikan seksual pada anak usia dini di TK al irsyad al Islamiyah Kabupaten Pemalang. Skripsi. Semarang : Fakultas Kesehatan Universitas Dian Nuswantoro. http://eprints.dinus.ac.id/22645/

KPAI. 2017. Tahun 2017, KPAI Temukan 116 Kasus Kekerasan Seksual Terhadap Anak. http://www.kpai.go.id/berita/tahun-2017-kpai-temukan116-kasus-kekerasan-seksual-terhadap-anak

KPAI, 2018. KPAI: Jangan Tabu Kenalkan Seks Pada Anak, Begini Caranya. http://www.kpai.go.id/berita/kpai-jangan-tabu-kenalkan-seks-pada-anakbegini-caranya

Muhsinin, U. 2017. Peran Ibu dalam Pengenalan Pendidikan Seks pada Anak dalam Perspektif Islam. Fakultas Tarbiyah IAIN Sulthan Thaha Saifuddin Jambi. Jurnal Harakat An Nisa. Vol 2 No 1 (2017) http://www.lp2m-iainstsjambi.ac.id/ejournal/index.php/anNisa/article/view/134

Nawita, M. 2013. Bunda, Seks Itu Apa Sih? Cara Cerdas dan Bijak Menjelaskan Seks Pada Anak. Bandung. Yrama Widya.

Notoatmodjo, S. 2014. Ilmu Perilaku Kesehatan. Jakarta : Rineka Cipta 
Republika, 2015. KPAI: Pentingnya Pendidikan Seksual Bagi Anak Sejak Usia

Dini. https://republika.co.id/berita/gaya-

hidup/parenting/15/09/30/nvh18h328-kpai-pentingnya-pendidikan-seksualbagi-anak-sejak-usia-dini

Sugiasih, I. (2011). Need Assessment Mengenai Pemberian Pendidikan Seksual Yang Dilakukan Ibu Untuk Anak Usia 3-5 Tahun. Jurnal Psikologi Proyeksi, $6(1)$.

Wawan, A \& Dewi. 2011. Pengetahuan, Sikap dan Perilaku Manusia. Yogyakarta : Nuha Medika

Yafie, E. 2017 Peranan Orang Tua Dalam Memberikan Pendidikan Seksual Anak Usia Dini.

Jurnal Care, Vol 4, No 2 (2017)

http://e-journal.unipma.ac.id/index.php/JPAUD/article/view/956/0 